\title{
Invited review: A systematic review of the effects of prolonged cow-calf contact on behavior, welfare, and productivity
}

\author{
Rebecca K. Meagher, ${ }^{1}$ Annabelle Beaver, ${ }^{2}$ Daniel M. Weary, ${ }^{2}$ and Marina A. G. von Keyserlingk ${ }^{2 *}$ \\ ${ }^{1}$ School of Agriculture, Policy and Development, University of Reading, Reading, Berkshire, RG6 6AR United Kingdom \\ ${ }^{2}$ Animal Welfare Program, Faculty of Land and Food Systems, University of British Columbia, Vancouver, BC, Canada V6T 1 Z4
}

\section{ABSTRACT}

Separation of calves from cows within hours or days of birth is common on dairy farms. Stakeholders have conflicting perspectives on whether this practice is harmful or beneficial for the animals' welfare and production. Our objective was to critically evaluate the scientific evidence for both acute and long-term effects of early separation versus an extended period of cow-calf contact. The outcomes investigated were the behavior, welfare (excluding physical health), and performance (milk yield and growth, respectively) of dairy cows and calves. Primary research papers were found through targeted Web of Science searches, the reference lists of recent reviews for each topic, and the reference lists of papers identified from these sources. Studies were included if they were published in English, the full text was accessible, and they compared treatments with and without contact between dairy cows and calves for a specified period. Early separation (within $24 \mathrm{~h}$ postpartum) was found to reduce acute distress responses of cows and calves. However, longer cow-calf contact typically had positive longer-term effects on calves, promoting more normal social behavior, reducing abnormal behavior, and sometimes reducing responses to stressors. In terms of productivity, allowing cows to nurse calves generally decreased the volume of milk available for sale during the nursing period, but we found no consistent evidence of reduced milk production over a longer period. Allowing a prolonged period of nursing increased calf weight gains during the milk-feeding period. In summary, extended cow-calf contact aggravates the acute distress responses and reduces the amount of saleable milk while the calves are suckling, but it can have positive effects on behaviors relevant to welfare in the longer term and benefit calf growth. The strength of these conclusions is limited, however, given that relatively few studies address most

Received November 20, 2018.

Accepted March 26, 2019.

*Corresponding author: nina@mail.ubc.ca of these effects and that experimental design including timing of contact and observations are often inconsistent across studies. Few studies presented indicators of long-term welfare effects other than abnormal and social behavior of the calves.

Key words: public attitudes, animal behavior, animal welfare, maternal care, growth

\section{INTRODUCTION}

A long-standing debate centers on the relative benefits of early separation of cows and calves (e.g., see Henderson and Reaves, 1954). In their review of this management practice, Flower and Weary (2003) summarized 4 of the main reasons for employing it. First, early separation is thought to increase financial profits, given that this practice allows the harvest (and sale) of milk that calves would otherwise drink. Second, feeding calves artificially allows control and monitoring of the quantity and quality of colostrum consumed, ensuring that intake is adequate for the passive transfer of immunity. Third, efficient milking requires that cows let down their milk soon after the milking equipment is attached, and milk let-down is thought to be facilitated by separating the calf. Finally, if the mother-infant bond develops slowly in the hours and days after calving, early separation is thought to minimize the distress response for both the cow and calf. This set of reasons reflect the intuitions of the authors cited by Flower and Weary (2003), but recent research has begun to more formally assess the views of farmers and others regarding this practice to better understand why the practice is employed and why some stakeholders oppose it. Thus, our first aim in the current review is to briefly summarize the literature on attitudes to early separation, with a second aim of identifying specific areas in which biological research may best inform the debate.

\section{ATTITUDES TO EARLY SEPARATION}

One study (Hötzel et al., 2014) conducted in-depth interviews with 20 smallholder dairy farms in Brazil. 
These participants cited human factors such as saving time and labor, improved milking routine, and tradition, as well as animal factors such as reduced calf stress as motivators for prompt cow-calf separation. Canadian veterinarians participating in focus groups to discuss issues relating to dairy cattle welfare voiced their support for cow-calf separation on the basis that they perceived that separating calves to be housed individually and hand-feeding colostrum improved calf health (Sumner and von Keyserlingk, 2018).

In contrast, some recent studies have indicated that cow-calf separation elicits significant concern from the public. Ventura et al. (2013) recruited a heterogeneous sample of primarily North American participants (with and without contact with the dairy industry), and asked "Should dairy calves be separated from the cow within the first few hours after birth?" Most participants $(76 \%)$ with no involvement in the industry were opposed to the practice. Similarly, a study of Brazilian citizens who reported no involvement with the dairy industry (Hötzel et al., 2017) and one of German and US participants, of which approximately $8 \%$ worked in agriculture (Busch et al., 2017), found that 55 to $69 \%$ of participants across studies were in favor of keeping cows and calves together. Ventura et al. (2016) asked 50 Canadian participants with little prior knowledge of dairy farming to describe their concerns about dairy production before and after visiting a commercial farm. Participants were largely unaware of separation practices before the visit, but early separation emerged as a concern after people had toured the farm.

The rationale for opposition to separation seems to focus predominantly on animal welfare. In the North American study by Ventura et al. (2013), the responses of participants exhibited 6 themes: cow and calf emotional responses, calf health, cow health and production, natural living, dissatisfaction with industry motivations, and changeability of farming systems. In a follow-up study, Busch et al. (2017) used these same themes to probe US and German participants and found that participants who opposed early separation were more likely to agree with the statements "The cow has an emotional attachment to her calf" and "Housing systems on dairy farms can be changed to maximize benefits for cows and calves," while participants in favor of early separation appeared to be most influenced by the statement "It is better for cow and calf to separate early because later separation is very hard on the mother."

Thus, many stakeholders express concern regarding early separation, while others make both ethical and economic arguments in defense of the practice. This work has confirmed that economic and calf health ef- fects are key components of the rationale for the practice, as was suggested by Flower and Weary (2003). In addition, the collective work on attitudes shows a high level of concern for animal welfare, including but not limited to acute distress responses at separation. The effects on cow and calf health have already been addressed in a separate systematic review in this issue (Beaver et al., 2019), which concluded that little evidence exists in support of the common belief that immediate separation is best for calf health. In addition, the results of this latter review indicated that a prolonged period of cow-calf contact has advantages for cow health. However, no review to date has critically examined the overall effects on other aspects of animal welfare, including a consideration of longer-term effects. Such a review may help resolve conflicting stakeholder views and highlight areas that need more work. Thus, the second aim of this paper is to systematically review the evidence relating to the effects of prolonged cow-calf contact on behavior and welfare, including both acute responses and any longer-term effects, and the effects on productivity, including cow milk production and calf BW gains, that are likely to affect the economic performance of the farm.

\section{METHODS FOR THE SYSTEMATIC REVIEW}

\section{Literature Search}

We conducted separate Web of Science searches for papers. All searches included the following terms: (cow-calf OR cow/calf OR dam-calf OR dam/calf OR "dam rearing" OR "reared by the dam" OR "reared by cows" OR "suckling system*" OR "mother rearing" or "reared by the mother" or "calf contact with adult*") AND (contact OR nurs* OR suckl*) AND (calf OR calves). To identify papers describing acute responses to separation at different ages, we used these terms in combination with the following search term: removal OR separation OR weaned. To identify papers relevant to the longer-term effects on cow and calf welfare and behavior, we used the following specific search terms: welfare OR well-being OR wellbeing OR stress* OR fear* OR "affective state" OR emotion*. The results of this search were considered separately depending on the type of putative welfare measures assessed (social behavior, abnormal behavior, and reaction to stressors). Finally, to identify papers relevant to the effects of early separation on measures of productivity, we used the following search terms: "milk production" OR "milk yield" OR growth OR "average daily gain" OR "liveweight gain." 


\section{Inclusion Criteria}

This systematic review includes only peer-reviewed articles that presented primary research on dairy cattle comparing groups with some form of cow-calf contact to those without. In addition, all articles were written in English and their full text was available. The literature search was completed on May 31, 2018, and papers published at any time up to that date were included. For each search, we scanned the titles and abstracts of articles that fit the above criteria to remove any that did not address any of the effects listed above. The text of the remaining papers was evaluated for relevance; those that provided primary data for any of the effects of interest were included. If the full text could not be accessed online, it was requested via ResearchGate. Because terminology used to describe cow-calf contact is so variable, it was not feasible to include all possible options in the search. Further, some older studies did not have searchable abstracts and keywords. Consequently, identifying all relevant papers with a search engine was not possible. We therefore also considered and included relevant references cited in the reviews by von Keyserlingk and Weary (2007), Newberry and Swanson (2008), and Johnsen et al. (2016). The reference lists of the papers selected for inclusion (and thus likely to discuss relevant literature) were scanned for additional relevant manuscripts that met the above criteria. The screening of articles was performed by the first author, with initial scanning of reference lists performed by a second person to rule out unusable sources, such as those written in other languages.

Given the relatively few studies available on this topic, no inclusion criteria were set based on study quality, with the only exception being studies in which the description of the study design was too vague to allow for interpretation (e.g., Lima et al., 2009). A quality assessment of the included manuscripts was conducted, considering reporting of methods of avoiding biases and relevant experimental design features (see Appendix). These exclusion and inclusion criteria were developed a priori and were agreed upon by all co-authors; when relevance was questionable, co-authors came to a consensus.

\section{Data Extraction}

The lead author extracted from each paper the sample size, breed of cattle used (any reported as "Holstein," "Friesian," or "Holstein-Friesian" being pooled as "HF"; any Bos taurus indicus breeds pooled as "zebu"), the type of cow-calf contact allowed (free contact $=$ social contact with the dam or foster dam(s) for at least half the day with suckling permitted; restricted suckling
$=$ short daily periods of contact for suckling; social $=$ housing together but suckling prevented), and the duration of this contact, along with duration of contact for the control calves (conventional early separation/ nonsuckling group). If control calves were reported as being removed "immediately," duration of contact was recorded as $<24 \mathrm{~h}$. If applicable, we reported the amount of milk and colostrum fed to calves in the control condition and the weaning protocol. We present the relevant conclusions as described by the authors and the reported direction of the effect. We use footnotes to the results tables to note any cases in which authors' conclusions are not supported by reported statistics. Interobserver reliability of data extraction was confirmed using a random sample of articles across all searches.

\section{RESULTS AND DISCUSSION FOR THE SYSTEMATIC REVIEW}

\section{Acute Responses}

Search Results. A flowchart summarizing the number of papers found, screened, and included across all searches is presented in Figure 1. Of the 99 studies found in the initial search for acute responses to separation, 9 were excluded because they were not primary research papers, 11 because they were not written in English, and an additional 32 because they were not on dairy cattle. Only 2 of the remaining papers directly compared responses to separation at different periods after calving without confounding factors such as 1 group being put through a 2 -step weaning procedure. Two more were added from the references of von Keyserlingk and Weary (2007).

Synthesis of Findings. All 3 studies comparing separation at $1 \mathrm{~d}$ of age or less with later separation reported early separation reduced distress responses, such as vocalizations and time looking out of the pen, in cows and calves (Table 1 ). Only 1 study compared later separation between different ages; this study found that separation at $25 \mathrm{~d}$ resulted in a stronger response, including increased frequency of vocalizations from both calves and cows, than separation at $45 \mathrm{~d}$ (Pérez-Torres et al., 2016). In this study, unlike those with younger calves, separation was apparently combined with weaning from milk. One possible explanation for the finding of later separation reducing distress responses is, as suggested by Stěhulová et al. (2017), the cow being more distressed by the removal of a calf that is more dependent upon maternal care.

One challenge with the reviewed studies is that calf age is typically confounded with time spent with the dam; older calves may behave differently than younger ones independent of separation because of changes 
in their physical strength and nutritional needs. To avoid such confounding, future work should include age-matched controls. The use of additional measures to characterize the acute negative response to separation, such as increased eye white in cows (Sandem and Braastad, 2005) and pessimistic cognitive biases in calves (Daros et al., 2014), could broaden the research on age comparisons.

\section{Longer-Term Effects on Behavior and Welfare}

Search Results. The initial search identified 54 papers. Of these, 7 were excluded because they were reviews or conference abstracts, 14 because they were in other languages, 12 because they did not contain data on dairy cattle, 13 because of lack of relevance to the objectives, and 2 because they did not provide key

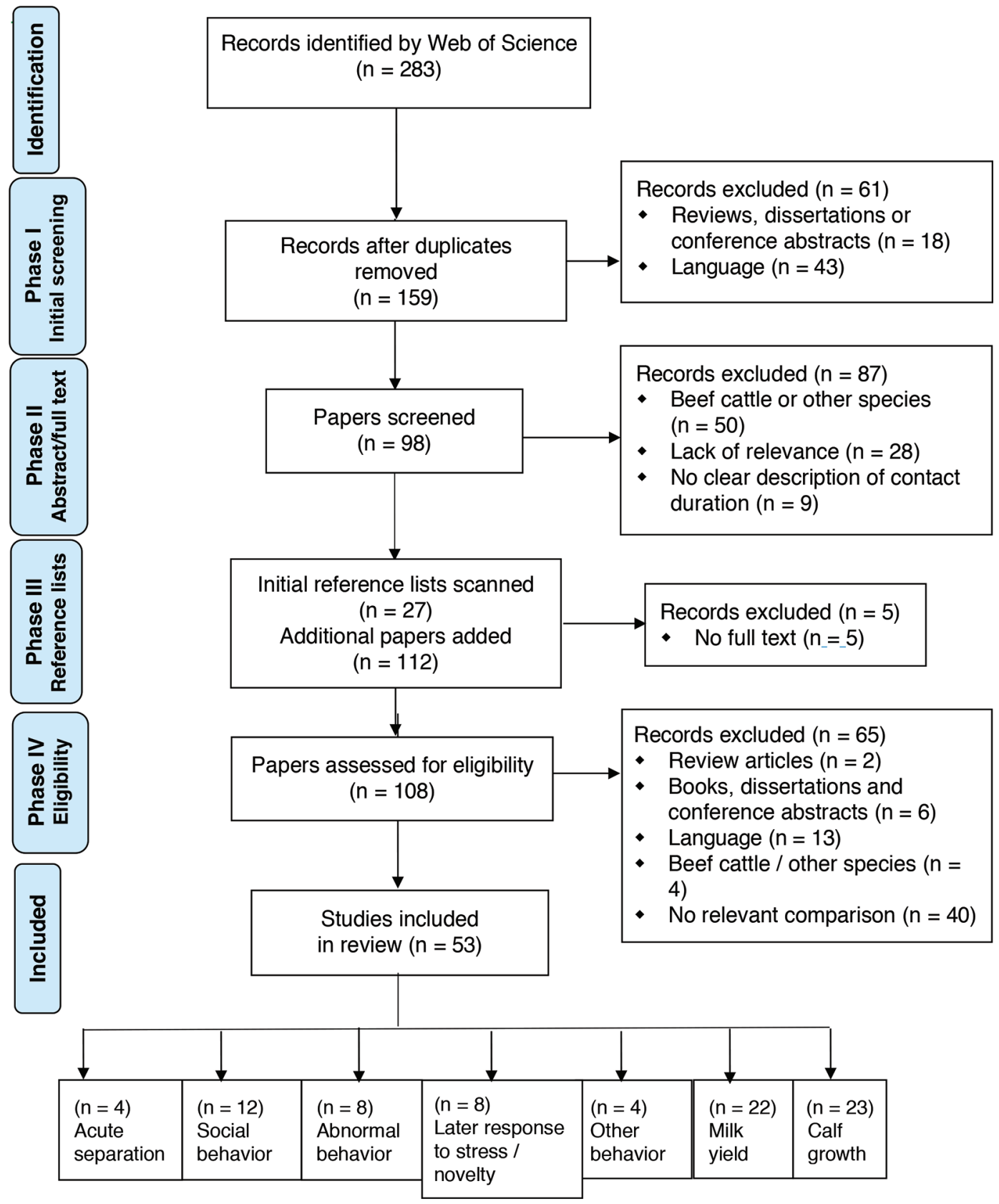

Figure 1. Flowchart depicting the manuscript screening and appraisal process. Note that the sum of the studies in each subsection of the studies included yields 81 studies, not 53 . This difference arises from the inclusion of 20 studies in 2 specific sections and 2 studies in 4 specific sections. Deleting the duplicates yields the total of 53 unique studies included in this review. 
INVITED REVIEW: EARLY SEPARATION-WELFARE AND PRODUCTION

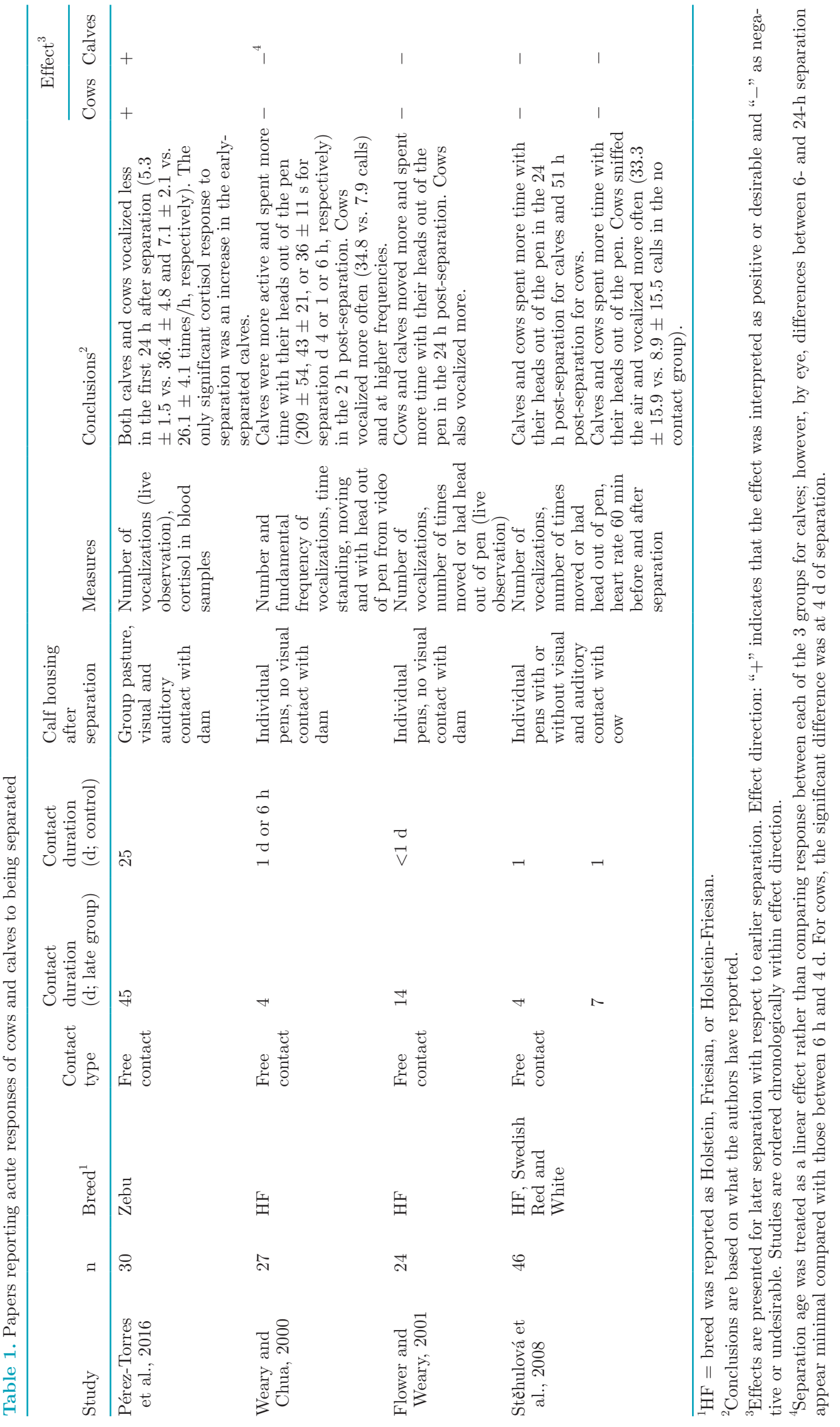


information about the treatments. Six usable papers remained. Five more were added from the reference list of the Johnsen et al. (2016) review, and 13 from the reference lists of the papers included from those sources, for a total of 24 papers. Because the variables measured were diverse and could have different interpretations with respect to welfare, results are presented separately within Table 2 for social behavior, abnormal behavior, and responses to novelty and other stressors. All these papers focused on the calves, with just one assessing effects on the mothers.

Findings: Social Behavior. Of the 12 studies identified, 10 reported effects of extended cow-calf contact that were considered beneficial, such as increased social interaction. One study reported both benefits and drawbacks to extended contact, one reported a negative effect (on successful feeding in a competitive situation), and the last reported no differences in any measures. The benefits reported did not typically include reductions in agonistic interactions or increased socio-positive behaviors. Increased submissive responses toward unfamiliar, older animals were considered more appropriate social behaviors in 2 studies (Krohn et al., 1999; Wagner et al., 2012). While most studies compared offspring that had contact with their mothers versus a single form of artificial rearing, 2 studies that included both individual and social rearing controls (Krohn et al., 1999; Duve et al., 2012) found that social rearing with other calves was as effective for the development of social behavior as rearing with the dam. Thus, maternal contact has potential to promote normal social behavior, but other forms of social contact may also be effective.

Findings: Abnormal Behavior. Eight papers measured abnormal oral behavior, including cross sucking, nonnutritive sucking, and tongue rolling, in the calves. Of these, 7 recorded behavior while calves had contact with the cow. Four recorded it after separation, for periods ranging from $3 \mathrm{~d}$ (pooled with the preweaning period; Fröberg et al., 2011) to 105 d (Roth et al., 2009). Studies reported reduced abnormal oral behaviors in calves allowed prolonged contact with the cow, with 2 exceptions finding no effect: one for calves that previously had free contact for half the day (Veissier et al., 2013), and another for calves that had only social contact (without suckling; Krohn et al., 1999). Thus, when calves were allowed full contact including suckling, abnormal oral behavior was consistently reduced both during and after the suckling period.

Findings: Response to Potential Stressors. Seven papers were identified that assessed responses to novelty and other potential stressors in offspring raised with and without maternal contact; one of these papers also examined responses of the dam. The timing of the tests ranged from during the milk-feeding period to the day of weaning and $2.5 \mathrm{yr}$ after birth (approximately 5 mo after the offspring had themselves given birth). All but 2 papers reported some benefit (such as reduced stress or fear responses) of prolonged contact with the dam. A potential drawback to mother rearing, in the form of increased active escape attempts during isolation, was reported by Wagner et al. (2013). These authors also noted 1 possible indicator of increased stress (self-licking) when the cows were later placed in a novel environment with an unfamiliar calf. Le Neindre (1989b) found increased inactivity and avoidance of the center of a test arena by cows that had been motherreared as calves, as well as higher respiratory rates. Activity was tentatively suggested to reflect disturbance, but whether these variables were related to fear is not known, and the authors acknowledged that they were difficult to interpret. Only one study looked at maternal response to stressors, using cortisol responses to restraint. Although this study reported no difference in cortisol between cows that had suckled a calf for 2 mo and those that had experienced immediate separation, this restraint may not have been a sufficiently intense stressor to detect effects because neither group showed a significant rise in cortisol (Orihuela and Hernández, 2007). Effects of longer contact between the cow and calf on responses to stressors are therefore mixed for calves, and too little information is available to draw conclusions regarding effects on the mothers.

Findings: Other Behavioral and Physiological Responses. A few relevant studies did not fit into the 3 categories described above. Lidfors (1996) reported that calves left with their dams to suckle for $4 \mathrm{~d}$ stood earlier, spent less time lying, vocalized less in the first hours of life, and licked themselves less, while cows also spent less time lying but vocalized more in the first hours post partum. The self-licking in calves separated from the dams may be associated with the lack of maternal licking and grooming (cf. Mandel and Nicol, 2017) and would thus be relevant to this review. Hernández et al. (2006) reported lower cortisol levels after suckling but faster heart rates just before milking in calves on a restricted suckling system versus those artificially reared, and lower cortisol levels in the dams who had suckled calves in the $5 \mathrm{~d}$ after cows and calves were separated. Calves left with the mother for $4 \mathrm{~d}$ were less likely to voluntarily contact a human at 25 wk and were harder to approach at 15 to 18 mo of age (Krohn et al., 1999). Finally, nursing itself has short-term physiological effects that might affect welfare. Specifically, Lupoli et al. (2001) found a release of oxytocin in both cows and their calves during nursing as well as reduced cortisol in the calves; however, baseline levels did not differ from cow-calf pairs that had been separated from one another. These effects need to be assessed in combi- 
INVITED REVIEW: EARLY SEPARATION—WELFARE AND PRODUCTION

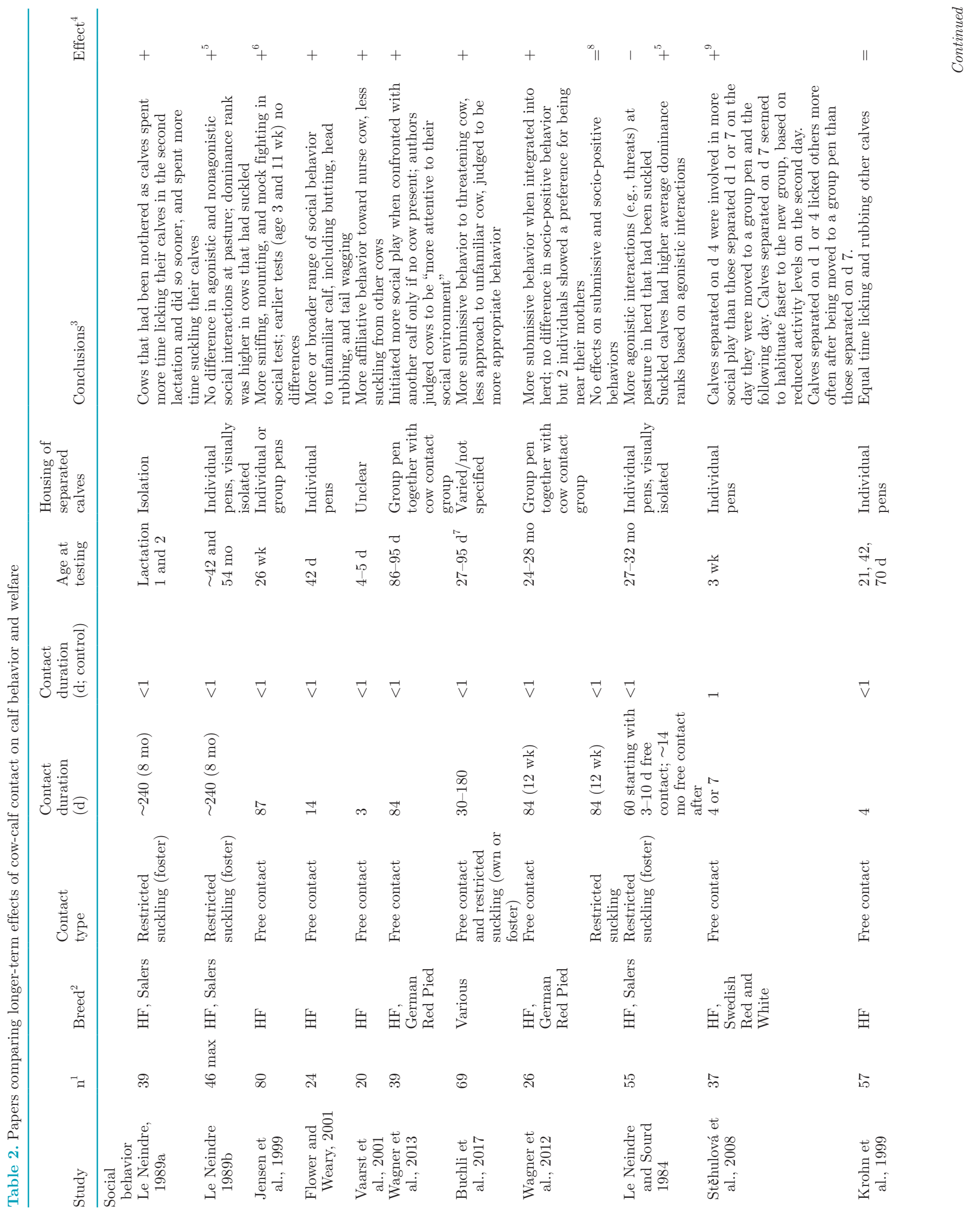




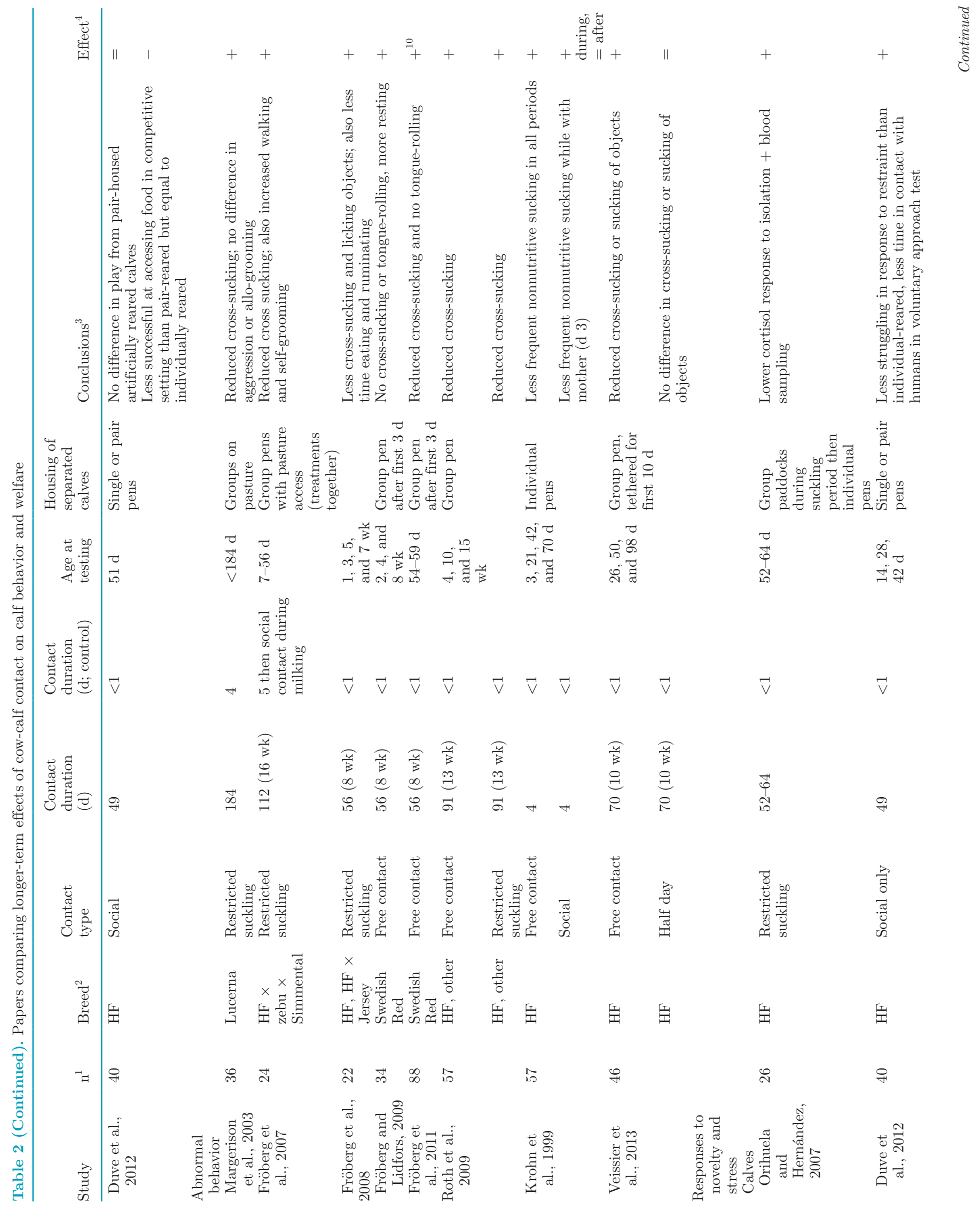


INVITED REVIEW: EARLY SEPARATION—WELFARE AND PRODUCTION

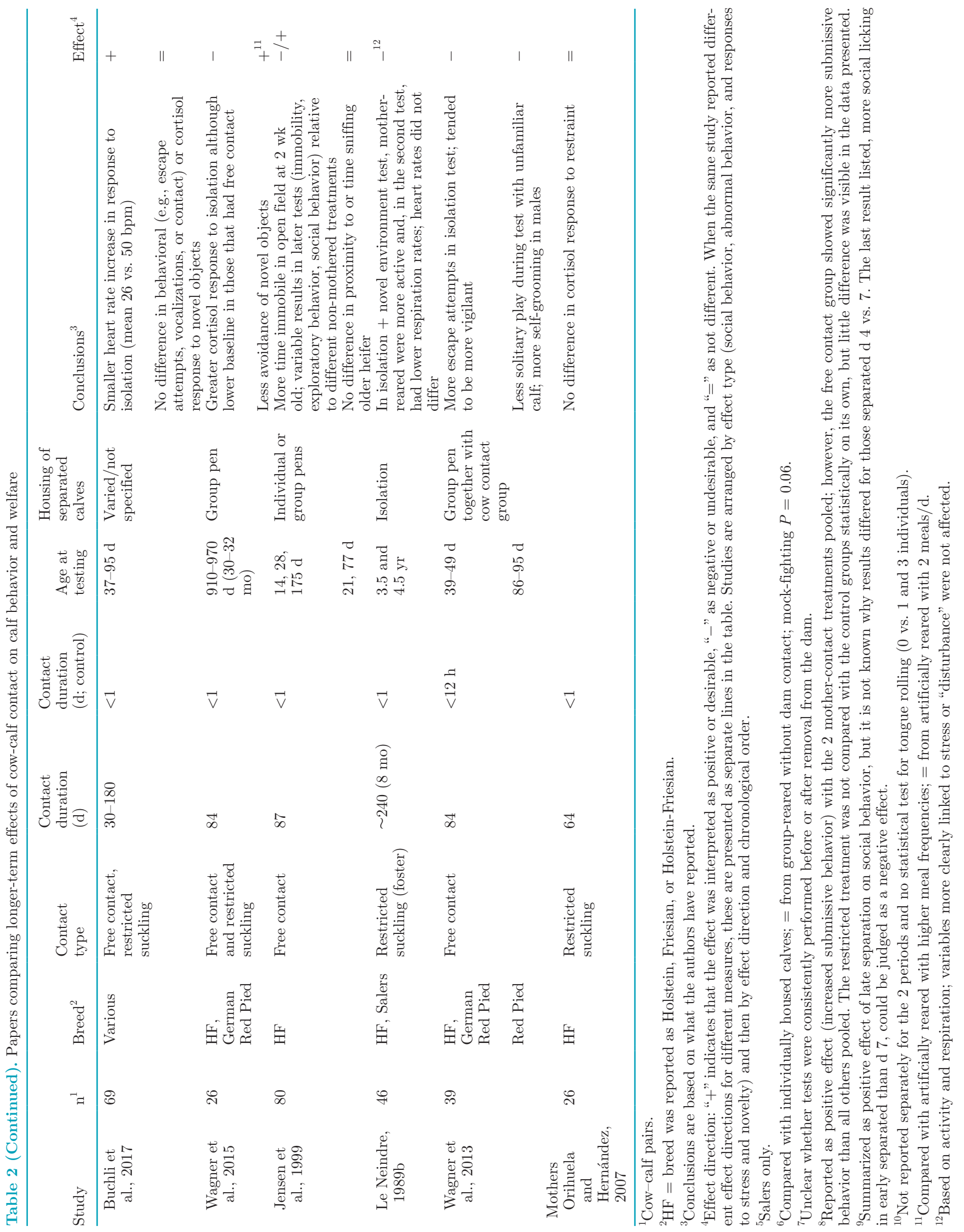




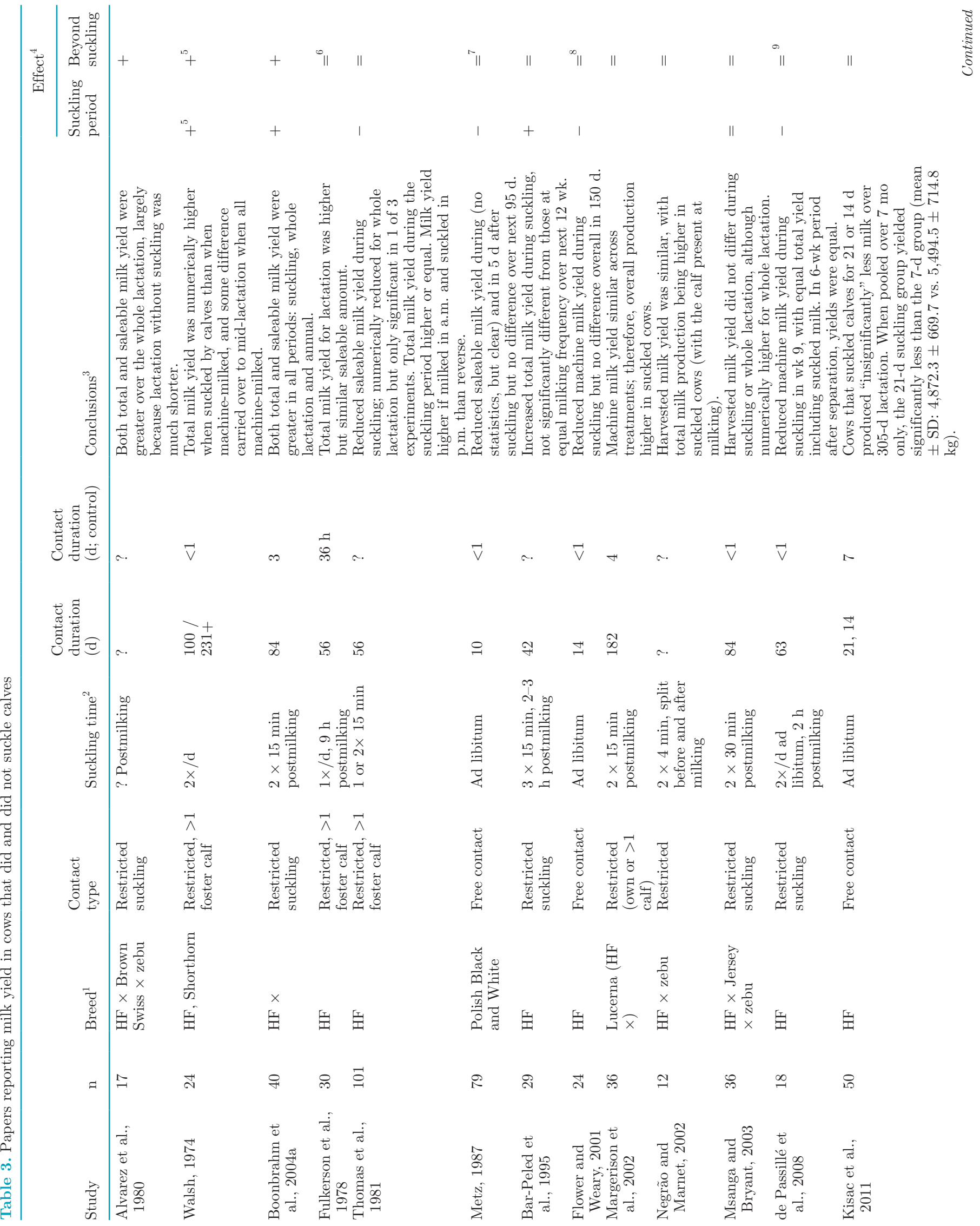


INVITED REVIEW: EARLY SEPARATION—WELFARE AND PRODUCTION
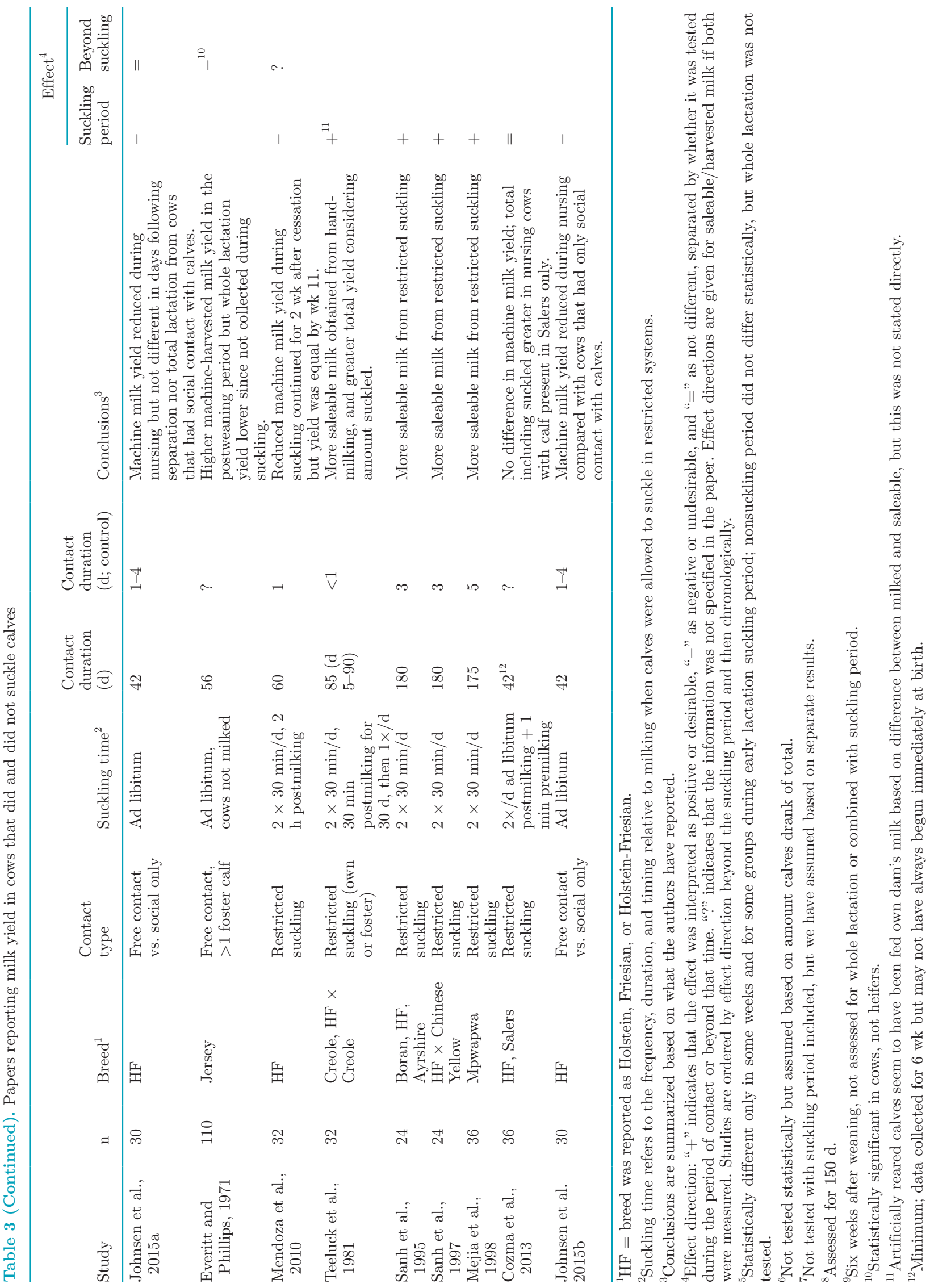


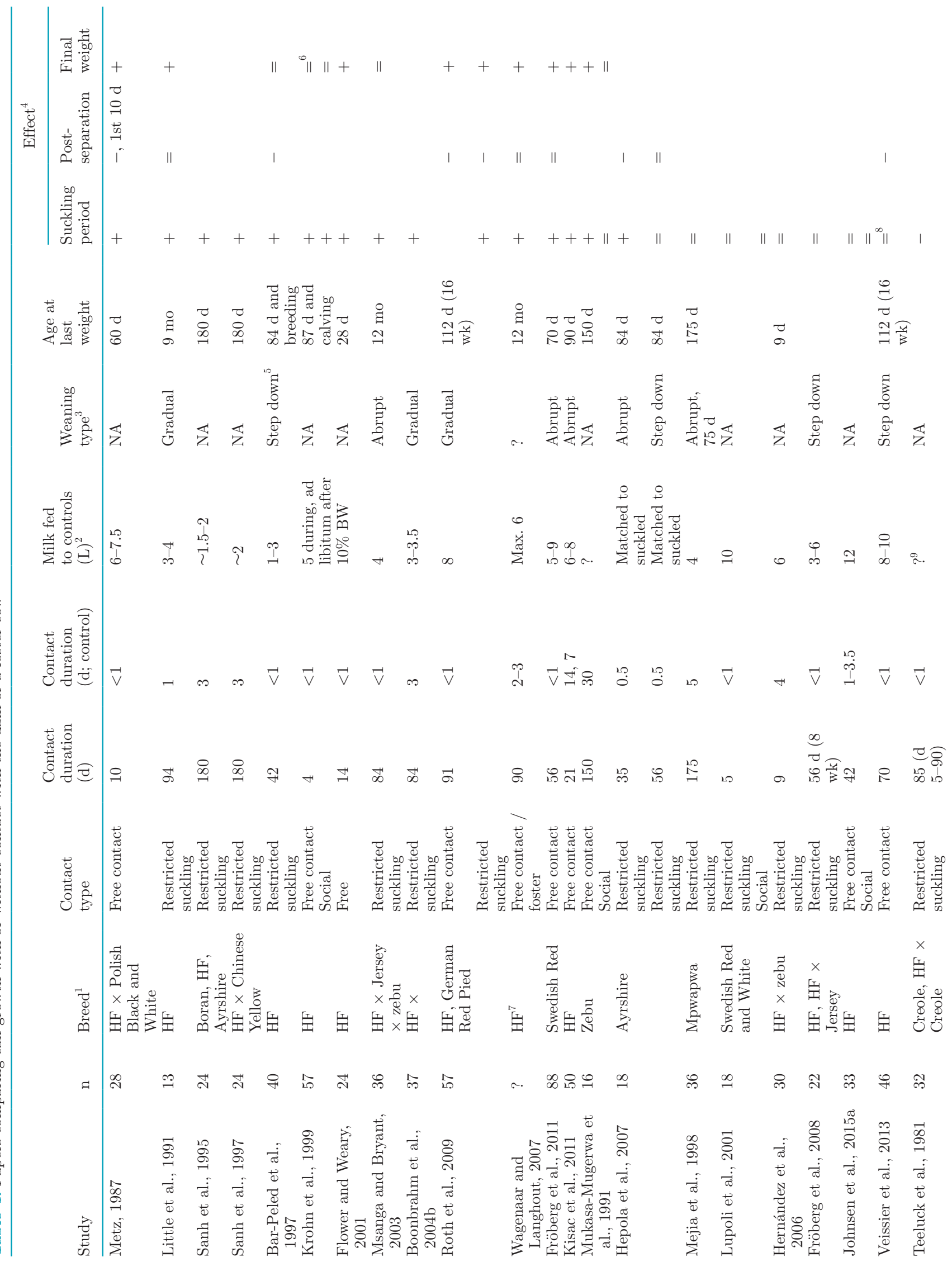


nation with other welfare measures to draw conclusions about their significance.

\section{Milk Yield}

Search Results. The search regarding milk yield produced 58 results. Of these, 7 were excluded because they were reviews or conference abstracts, 4 because they were in other languages, 12 because they were not on dairy cattle, and 2 because they did not provide key information about the treatments. Of the rest, only 2 papers compared milk yield in cows that suckled calves versus those that did not; 7 additional papers were added from Johnsen et al. (2016) and 1 from von Keyserlingk and Weary (2007). An additional 12 papers were sourced from the reference lists of these papers, for a total of 22 papers.

Synthesis of Findings. Among papers focused on the suckling period, 7 reported decreases in harvested milk in cows allowed to nurse their calves, 7 reported increases, and 2 reported no difference. Fourteen papers assessed yield beyond the suckling period, ranging from 3 wk post separation to the full 305-d lactation (Table 3). Everitt and Phillips (1971) reported a reduction over the full lactation in multiparous cows, and 3 other papers reported increases. One of these papers (Walsh, 1974) must be viewed with caution given that the difference in the nonsuckling period was not statistically significant. The remaining studies reported no statistically significant differences in long-term yield after separation. We found no consistent evidence of a negative effect of cow-calf contact on milk production over a longer period. Moreover, any acute reduction in milk yield (during the suckling period) was likely due to the milk consumed by the calves; thus, any reduction in saleable milk can only truly be considered a loss if this intake exceeds what calves would have been fed through other methods. For farms feeding milk replacer, any difference in the relative costs of the milk versus milk replacer would need to be considered. The economic implications will therefore depend on whether farms feed milk at the increased volumes that are now recommended (Khan et al., 2011).

\section{Calf Growth}

Search Results. Of the 72 results from the initial search on calf growth, 5 were excluded because they were reviews or conference abstracts, 19 were not written in English, and 26 were not on dairy cattle. Of the remainder, just 2 papers compared growth in calves with or without maternal contact; 10 more relevant papers were identified from Johnsen et al. (2016), 1 from von Keyserlingk and Weary (2007), and 10 from 
the reference lists of these additional papers, for a total of 23 studies (Table 4).

Synthesis of Findings. Fourteen studies reported increased calf growth during the suckling period in calves that had extended contact with cows, 2 reported an increase or no effect in different groups, and 6 reported no change. Although Fröberg et al. (2008) found no differences in weight gains, they noted greater variability within the suckling group. The 2 studies that reported decreased calf growth for suckled calves compared with those that were artificially reared considered restricted suckling systems in which the suckled calves were only allowed access to the dam after milking and milk intake from suckling was low (averaging $2.15 \mathrm{~kg} / \mathrm{d}$ [Teeluck et al., 1981] and less than $1.5 \mathrm{~kg} / \mathrm{d}$ [Margerison et al., 2003]). Benefits for calf gain appeared to be specific to suckling; 2 of the 3 studies in which calves had social access to their dams but were not allowed to nurse found no effects of contact on growth. This result suggests that the increased weight gain in suckled calves is a result of greater milk intake. Solid feed intake was typically lower in the suckled calves than in limit-fed artificially reared calves (e.g., Margerison et al., 2002; Fröberg et al., 2011).

After calves were separated from the cows, the effects of cow-calf contact on gains are less clear. Some studies report reduced growth in suckled calves (see Table 4), particularly in the weeks immediately after weaning. This result was likely due to the challenge of weaning calves from high volumes of milk, while most artificially reared calves in these studies were fed restricted volumes. This growth check underscores the importance of developing better weaning protocols for these calves. Research on nutritional weaning has indicated that some form of gradual weaning, such as by reduced volume or dilution, can encourage intake of solid feed before milk feeding ends (see review by Khan et al., 2011). Abrupt weaning from milk at the same time as breaking the bond to the milk source (e.g., nipple in artificial rearing systems: Jasper et al., 2008 ) or social bond with the mother (Newberry and Swanson, 2008) is a known stressor. This stress can be reduced by separating the 2 processes, for example, by a placing nose-flap on the calf to prevent suckling some time before separation from the cow (beef cattle: Haley et al., 2005) or by delaying the removal of the nipple by a few days after milk removal in artificial milk rearing systems (Jasper et al., 2008). A reduction in growth rate compared with artificially reared calves was observed by Bar-Peled et al. (1997) even when the calves in the suckled treatment were transitioned to the same milk replacer diet $(8 \mathrm{~L} / \mathrm{d})$ as the control calves at separation. Although calves were still fed a milk diet, the amount was likely less and this reduction was ac- companied by a shift in the method of feeding. Despite the growth check at weaning, the majority of studies have reported that the benefits for growth during the suckling period, compared with separated calves, were maintained for weeks or months after separation. Given the importance of early growth for later production (Khan et al., 2011), this practice may benefit productivity.

\section{GENERAL DISCUSSION}

Although sufficient evidence is available for broad conclusions regarding effects of extending the period of contact between calf and cow on the outcomes described above, specific recommendations cannot be given regarding how long this period should be and which systems are most effective. It is reasonable to assume that contact duration and type (e.g., restricted suckling or full contact) might influence the results. However, these factors were variable across studies, and other differences in the methods or outcome variables mean that no clear pattern can be discerned. Nevertheless, short-term contact clearly has some lasting effect: 2 studies (Krohn et al., 1999; Stěhulová et al., 2008) reported that just $4 \mathrm{~d}$ of contact reduced abnormal or increased normal social behavior weeks later, and Flower and Weary (2001) reported a similar effect of 2 wk of contact. While the effects of nursing on milk yield over the entire lactation will likely depend on how much and for how long calves are allowed to suckle, the studies reporting positive long-term effects on yield were among those with the longest suckling duration. With respect to contact type, sufficient data did not exist for ascertaining differences between systems. Relatively few studies looked at calves fostered by nurse cows, and this variable was confounded with amount of contact because these calves were all in restricted suckling systems. Restricted suckling systems also had considerable variation in how much time calves were able to suckle each day and when suckling happened relative to milking. More systematic investigation of these factors is needed to determine which systems are best for welfare and production.

The age of some studies may also limit the relevance of the evidence. For milk yield specifically, many of the papers found were more than $20 \mathrm{yr}$ old, which may influence the results given the genetic gains made for increased milk yield in recent decades (Oltenacu and Broom, 2010). Fewer studies conducted in the last 20 yr report increased milk yields in suckled cows (with the exception of Boonbrahm et al., 2004a), but this increase is confounded with breed because more recent studies have focused on Holsteins. 
Before recommendations for specific systems of cowcalf contact can be made, we suggest that the effects of repeated separation still need to be investigated because systems allowing contact for part of the day may be practical for farmers. Such restricted contact systems allow for some benefits of cow-calf contact while still encouraging independence from the dam to ease the transition at weaning (Newberry and Swanson, 2008; Veissier et al., 2013). Half-day systems, which are as yet little studied, seem to offer some practical advantages because they may offer many of the same benefits as full contact while allowing harvesting of some milk and interventions to ease the weaning process, as suggested by Johnsen et al. (2016). However, given that repeated maternal separation is used as a model for chronic stress in rodents (e.g., Nishi et al., 2014), it is worth testing whether it may also have a negative impact on the calves (or dams) compared with full-day cow-calf contact, and whether the length of separation (e.g., a half day versus only for milking) is important. Cattle may be tolerant to short-term separation due to their species ecology because cows typically leave young calves while grazing (Vitale et al., 1986).

The available evidence for calves suggests potential long-term welfare benefits to contact with the cow beyond the first days of life. Studies mentioning welfare, stress, or related terms report a variety of behavioral and physiological measures; the clearest evidence is for reductions in abnormal behavior. However, the relevance of these results to the welfare of the calves is not always clear. For example, while vocalization after separation is typically considered indicative of distress, the increased vocalizations from cows soon after giving birth when the calf is still present (Lidfors, 1996) is likely a positively valenced social behavior with beneficial effects. Within the social behavior category, what was considered desirable varied among studies, with high dominance and submissive behavior both considered positive depending on the context. The range of outcomes assessed is also limited, with few studies directly assessing subjective states. Responses to stress and pain constitute one area that requires further work. Studies on rodents show that low levels of maternal care (licking and grooming) and deprivation of maternal care due to repeated separation are associated with increased hormonal (hypothalamic-pituitaryadrenal axis) responses to stress and increased signs of fear or anxiety such as elevated startle responses in the offspring when tested as adults (reviewed by Meaney, 2001; Sachser et al., 2011). These effects can even persist in future generations, likely because offspring that received little maternal care perform less of this behavior toward their own offspring (Meaney, 2001). Maternal care can also reduce adult sensitivity to pain in rodents (e.g., de Medeiros et al., 2009), while repeated separation from the mother can cause hypersensitivity to pain (Moloney et al., 2012). Such effects have not been investigated in dairy cattle.

Social skills and dominance are influenced by social conditions during rearing in a range of species from rhesus macaques (Bastian et al., 2003) to cichlids (Arnold and Taborsky, 2010). As we have reviewed above, the studies to date do not show consistent effects of maternal contact in dairy cattle, although the differences that were found were generally positive. More work with large sample sizes would be helpful, particularly in distinguishing between the effects of maternal contact and other types of social contact.

Social learning abilities have not yet been investigated in cattle. In rats, maternal deprivation causes deficits in social learning (Lévy et al., 2003; Melo et al., 2006). Even in spiders, maternal contact seems to improve learning (Punzo and Ludwig, 2002). Work on calves indicates that early social contact, including maternal contact, improves flexibility of learning, but peer contact might be equally effective (Meagher et al., 2015). No studies have compared social learning in dam-reared calves to those separated from the dam, whether reared individually or in peer groups. This topic may be particularly worthy of investigation given the known effects of the dam in offspring learning how and where to feed (Provenza and Balph, 1987) and the role that feeding behavior plays in milk production and growth.

With the exception of Le Neindre (1989a), who showed an increase in adult maternal behavior of damreared Salers cows, little work has been done on how maternal care affects the calves' own maternal behavior when they are adults. Although some suggest that modern dairy cattle express less maternal behavior (perhaps due to relaxed selection pressure on this trait), little empirical data support this assertion (Rørvang et al., 2018). Any reductions in maternal behavior may result from not being permitted to experience maternal behavior or from differences in the environment in which the observations are conducted. Investigations of maternal behavior should consider the effects across more than a single generation.

This review suggests that a need exists for broader investigations into the welfare of cows after separation. This work could include, for example, altered stress responsiveness; work on laboratory animals (e.g., Windle et al., 1997) suggests that the hypothalamic-pituitaryadrenal axis is hyporesponsive throughout lactation, but this may depend in part on suckling, which reduces stress responsiveness in human women (Heinrichs et al., 2001). To our knowledge, no research on cattle has investigated postpartum depression. Depression in hu- 
mans is well known to render an individual susceptible to secondary illnesses, possibly by means of suppressing the immune system (Stein et al., 1991), and the postpartum period is when women are most at risk of becoming depressed (Dikmen-Yildiz et al., 2018). Additional evidence linking depression to disease in humans comes from work by Musselman et al. (1998) who linked impaired immunity in chronic depression to greater risk of developing cardiovascular diseases. Some signs associated with depression in humans may help inform predictions to be tested in cattle, including reduced appetite, low activity, a disturbance in normal sleeping patterns, loss of libido, and anhedonia (reviewed by Miller, 2002; Field, 2010). One theory that has gained some traction in human medicine is that high levels of stress resulting in high levels of corticosteroids pre- and postpartum are correlated with postpartum depression (Brummelte and Galea, 2010; Murgatroyd and Nephew, 2013); high levels of stress are arguably present in dairy cattle production systems, and they may be exacerbated by removing the calf. Understanding these stressors is important given the high rates of disease around the time of calving (LeBlanc, 2010).

\section{CONCLUSIONS}

Contrary to the expectations of some stakeholders, suckling often did not reduce saleable milk yield when measured over the long term, while calf growth was often improved by suckling. The effects of early separation versus extended cow-calf contact on behavior were mixed, and variables measured to date make it difficult to draw strong conclusions about overall welfare. Where effects on calf behavior were found, they were typically positive, but almost no long-term work on cow welfare is available. Very early separation can reduce the acute distress response in both cows and calves. Prolonged contact may provide longer-term benefits for calf growth and behavioral development, with no consistent evidence for a reduction in milk yield from the cow.

\section{ACKNOWLEDGMENTS}

We are grateful to Dairy Australia (Melbourne, Australia) for soliciting this review and for providing support to Rebecca Meagher and Annabelle Beaver. We also thank Angela Yu, Lara Sirovicia, and Auguste de Pennart (students at University of British Columbia) for their assistance. Angela Yu was supported by a Natural Sciences and Engineering Research Council (NSERC) Undergraduate Scholarship.

\section{REFERENCES}

Alvarez, F. J., G. Saucedo, A. Arriaga, and T. R. Preston. 1980. Effect on milk production and calf performance of milking cross bred European/zebu cattle in the absence or presence of the calf, and of rearing their calves artificially. Trop. Anim. Prod. 5:25-37.

Arnold, C., and B. Taborsky. 2010. Social experience in early ontogeny has lasting effects on social skills in cooperatively breeding cichlids. Anim. Behav. 79:621-630.

Bar-Peled, U., E. Maltz, I. Bruckental, Y. Folman, Y. Kali, H. Gacitua, A. R. Lehrer, C. H. Knight, B. Robinson, H. Voet, and H. Tagari. 1995. Relationship between frequent milking or suckling in early lactation and milk production of high producing dairy cows. J. Dairy Sci. 78:2726-2736.

Bar-Peled, U., B. Robinzon, E. Maltz, H. Tagari, Y. Folman, I. Bruckental, H. Voet, H. Gacitua, and A. R. Lehrer. 1997. Increased weight gain and effects on production parameters of Holstein heifer calves that were allowed to suckle from birth to six weeks of age. J. Dairy Sci. 80:2523-2528.

Bastian, M. L., A. C. Sponberg, A. C. Sponberg, S. J. Suomi, and J. D. Higley. 2003. Long-term effects of infant rearing condition on the acquisition of dominance rank in juvenile and adult rhesus macaques (Macaca mulatta). Dev. Psychobiol. 42:44-51.

Beaver, A., R. K. Meagher, D. M. Weary, and M. A. G. von Keyserlingk. 2019. Invited review: A systematic review of the effects of early separation on dairy cow and calf health. J. Dairy Sci. 102:5784-5810. https://doi.org/10.3168/jds.2018-15603.

Boonbrahm, N., K. J. Peters, and W. Intisang. 2004a. The influence of calf rearing methods and milking methods on performance traits of crossbred dairy cattle in Thailand 1. Milk yield and udder health. Arch. Tierzucht 47:211-224.

Boonbrahm, N., K. J. Peters, and C. Kijora. 2004b. The influence of calf rearing methods and milking methods on performance traits of crossbred dairy cattle in Thailand 3. Calf performance. Arch. Tierzucht 47:405-414.

Brummelte, S., and L. A. M. Galea. 2010. Chronic corticosterone during pregnancy and postpartum affects maternal care, cell proliferation and depressive-like behavior in the dam. Horm. Behav. 58:769-779.

Buchli, C., A. Raselli, R. Bruckmaier, and E. Hillmann. 2017. Contact with cows during the young age increases social competence and lowers the cardiac stress reaction in dairy calves. Appl. Anim. Behav. Sci. 187:1-7.

Busch, G., D. M. Weary, A. Spiller, and M. A. von Keyserlingk. 2017. American and German attitudes towards cow-calf separation on dairy farms. PLoS One 12:e0174013.

Cozma, A., B. Martin, M. Guiadeur, P. Pradel, E. Tixier, and A. Ferlay. 2013. Influence of calf presence during milking on yield, composition, fatty acid profile and lipolytic system of milk in Prim'Holstein and Salers cow breeds. Dairy Sci. Technol. 93:99113.

Daros, R. R., J. H. C. Costa, M. A. von Keyserlingk, M. J. Hoetzel, and D. M. Weary. 2014. Separation from the dam causes negative judgement bias in dairy calves. PLoS One 9:e98429.

de Medeiros, C. B., A. S. Fleming, C. C. Johnston, and C. Walker. 2009. Artificial rearing of rat pups reveals the beneficial effects of mother care on neonatal inflammation and adult sensitivity to pain. Pediatr. Res. 66:272-277.

de Passillé, A. M., P. G. Marnet, H. Lapierre, and J. Rushen. 2008. Effects of twice-daily nursing on milk ejection and milk yield during nursing and milking in dairy cows. J. Dairy Sci. 91:1416-1422.

Dikmen-Yildiz, P., S. Ayers, and L. Phillips. 2018. Longitudinal trajectories of post-traumatic stress disorder (PTSD) after birth and associated risk factors. J. Affect. Disord. 229:377-385.

Duve, L. R., D. M. Weary, U. Halekoh, and M. B. Jensen. 2012. The effects of social contact and milk allowance on responses to handling, play, and social behavior in young dairy calves. J. Dairy Sci. 95:6571-6581.

Everitt, G. C., and D. S. M. Phillips. 1971. Calf rearing by multiple suckling and the effects on lactation performance of the cow. Proc. N.Z. Soc. Anim. Prod. 31:22-40. 
Field, T. 2010. Postpartum depression effects on early interactions, parenting, and safety practices: A review. Infant Behav. Dev. 33:16.

Flower, F. C., and D. M. Weary. 2001. Effects of early separation on the dairy cow and calf: 2 . Separation at 1 day and 2 weeks after birth. Appl. Anim. Behav. Sci. 70:275-284.

Flower, F. C., and D. M. Weary. 2003. The effects of early separation on the dairy cow and calf. Anim. Welf. 12:339-348.

Fröberg, S., A. Aspegren-Guldorff, I. Olsson, B. Marin, C. Berg, C. Hernandez, C. S. Galina, L. Lidfors, and K. Svennersten-Sjaunja. 2007. Effect of restricted suckling on milk yield, milk composition and udder health in cows and behaviour and weight gain in calves, in dual-purpose cattle in the tropics. Trop. Anim. Health Prod. 39:71-81.

Fröberg, S., E. Gratte, K. Svennersten-Sjaunja, I. Olsson, C. Berg, A. Orihuela, C. S. Galina, B. Garcia, and L. Lidfors. 2008. Effect of suckling ('restricted suckling') on dairy cows' udder health and milk let-down and their calves' weight gain, feed intake and behaviour. Appl. Anim. Behav. Sci. 113:1-14.

Fröberg, S., and L. Lidfors. 2009. Behaviour of dairy calves suckling the dam in a barn with automatic milking or being fed milk substitute from an automatic feeder in a group pen. Appl. Anim. Behav. Sci. 117:150-158.

Fröberg, S., L. Lidfors, K. Svennersten-Sjaunja, and I. Olsson. 2011. Performance of free suckling dairy calves in an automatic milking system and their behaviour at weaning. Acta Agric. Scand. A Anim. Sci. 61:145-156.

Fulkerson, W. J., R. D. Hooley, and J. K. Findlay. 1978. Improvement in milk production of first calf heifers by multiple suckling. Aust. J. Agric. Res. 29:351-357.

Haley, D. B., D. W. Bailey, and J. M. Stookey. 2005. The effects of weaning beef calves in two stages on their behavior and growth rate. J. Anim. Sci. 83:2205-2214.

Heinrichs, M., G. Meinlschmidt, I. Neumann, S. Wagner, C. Kirschbaum, U. Ehlert, and D. H. Hellhammer. 2001. Effects of suckling on hypothalamic-pituitary-adrenal axis responses to psychosocial stress in postpartum lactating women. J. Clin. Endocrinol. Metab. 86:4798-4804.

Henderson, H. O., and P. M. Reaves. 1954. Dairy Cattle Feeding and Management. 4th ed. John Wiley \& Sons, Inc., New York, NY

Hepola, H., S. Raussi, I. Veissier, P. Pursiainen, K. Ikkeläjärvi, H. Saloniemi, and L. Syrjälä-Qvist. 2007. Five or eight weeks of restricted suckling: Influence on dairy calves' feed intake, growth and suckling behaviour. Acta Agric. Scand. A Anim. Sci. 57:121-128.

Hernández, C. A. Orihuela, S. Fröberg, and L. M. Lidfors. 2006. Effect of restricted suckling on physiological and behavioural stress parameters in dual-purpose cattle in the tropics. Livest. Sci. 99:2127.

Hötzel, M. J., C. S. Cardoso, A. Roslindo, and M. A. von Keyserlingk. 2017. Citizens' views on the practices of zero-grazing and cow-calf separation in the dairy industry: Does providing information increase acceptability? J. Dairy Sci. 100:4150-4160.

Hötzel, M. J., C. Longo, L. F. Balcao, C. S. Cardoso, and J. H. C. Costa. 2014. A survey of management practices that influence performance and welfare of dairy calves reared in southern Brazil. PLoS One 9:e114995.

Jasper, J., M. Budzynska, and D. M. Weary. 2008. Weaning distress in dairy calves: Acute behavioural responses by limit-fed calves. Appl. Anim. Behav. Sci. 110:136-143.

Jensen, M. B., L. Munksgaard, L. Mogensen, and C. C. Krohn. 1999. Effects of housing in different social environments on open-field and social responses of female dairy calves. Acta Agric. Scand. A Anim. Sci. 49:113-120.

Johnsen, J. F., A. M. de Passille, C. M. Mejdell, K. E. Bøe, A. M. Grøndahl, A. Beaver, J. Rushen, and D. M. Weary. 2015a. The effect of nursing on the cow-calf bond. Appl. Anim. Behav. Sci. 163:50-57.

Johnsen, J. F., K. Ellingsen, A. M. Grøndahl, K. E. Bøe, L. Lidfors, and C. M. Mejdell. 2015b. The effect of physical contact between dairy cows and calves during separation on their post-separation behavioural response. Appl. Anim. Behav. Sci. 166:11-19.
Johnsen, J. F., K. A. Zipp, T. Kälber, A. M. d. Passillé, U. Knierim, K. Barth, and C. M. Mejdell. 2016. Is rearing calves with the dam a feasible option for dairy farms? Current and future research. Appl. Anim. Behav. Sci. 181:1-11.

Khan, M. A., D. M. Weary,, and M. A. von Keyserlingk. 2011. Invited review: Effects of milk ration on solid feed intake, weaning, and performance in dairy heifers. J. Dairy Sci. 94:1071-1081.

Kisac, P., J. Broucek, M. Uhrincat, and A. Hanus. 2011. Effect of weaning calves from mother at different ages on their growth and milk yield of mothers. Czech J. Anim. Sci. 56:261-268.

Krohn. C. C., J. Foldager, and L. Mogensen. 1999. Long-term effect of colostrum feeding methods on behaviour in female dairy calves. Acta Agric. Scand. A Anim. Sci. 49:57-64.

Le Neindre, P. 1989a. Influence of cattle rearing conditions and breed on social relationships of mother and young. Appl. Anim. Behav. Sci. 23:117-127.

Le Neindre, P. 1989b. Influence of rearing conditions and breed on social behaviour and activity of cattle in novel environments. Appl. Anim. Behav. Sci. 23:129-140.

Le Neindre, P. and C. Sourd. 1984. Influence of rearing conditions on subsequent social behaviour of Friesian and Salers heifers from birth to six months of age. Appl. Anim. Behav. Sci. 12:43-52.

LeBlanc, S. 2010. Monitoring metabolic health of dairy cattle in the transition period. J. Reprod. Dev. 56:S29-S35.

Lévy, F., A. I. Melo, G. Galef, M. Madden, and A. S. Fleming. 2003. Complete maternal deprivation affects social but not spatial learning in adult rats. Dev. Psychobiol. 43:177-191.

Lidfors, L. M. 1996. Behavioural effects of separating the dairy calf immediately or 4 days post-partum. Appl. Anim. Behav. Sci. 49:269-283.

Lima, R., M. A. Hernandez, J. L. Rodriguez, and J. A. Betancourt. 2009. Behavior of dairy cows in different calf rearing systems in the period 2001-2006. Cuban J. Agric. Sci. 43:21-25.

Little, D. A., F. M. Anderson, and J. W. Durkin. 1991. Influence of partial suckling of crossbred dairy cows on milk offtake and calf growth in the Ethiopian highlands. Trop. Anim. Health Prod. 23:108-114.

Lupoli, B., B. Johansson, K. Uvnäs-Moberg, and K. SvennerstenSjaunja. 2001. Effect of suckling on the release of oxytocin, prolactin, cortisol, gastrin, cholecystokinin, somatostatin and insulin in dairy cows and their calves. J. Dairy Res. 68:175-187.

Mandel, R., and C. J. Nicol. 2017. Re-direction of maternal behaviour in dairy cows. Appl. Anim. Behav. Sci. 195:24-31.

Margerison, J. K., T. R. Preston, N. Berry, and C. J. C. Phillips. 2003. Cross-sucking and other oral behaviours in calves, and their relation to cow suckling and food provision. Appl. Anim. Behav. Sci. 80:277-286

Margerison, J. K., T. R. Preston, and C. J. C. Phillips. 2002. Restricted suckling of tropical dairy cows by their own calf or other cows' calves. J. Anim. Sci. 80:1663-1670.

Meagher, R. K., R. R. Daros, J. H. C. Costa, M. A. von Keyserlingk, M. J. Hötzel, and D. M. Weary. 2015. Effects of degree and timing of social housing on reversal learning and response to novel objects in dairy calves. PLoS One 10:e0132828.

Meaney, M. J. 2001. Maternal care, gene expression, and the transmission of individual differences in stress reactivity across generations. Annu. Rev. Neurosci. 24:1161-1192.

Mejia, C. E., T. R. Preston, and P. Fajersson. 1998. Effects of restricted suckling versus artificial rearing on milk production, calf performance and reproductive efficiency of dual purpose Mpwapwa cattle in a semi-arid climate. Livest. Res. Rural Dev. 10:8.

Melo, A. I., V. Lovic, A. Gonzalez, M. Madden, K. Sinopoli, and A. S. Fleming. 2006. Maternal and littermate deprivation disrupts maternal behavior and social-learning of food preference in adulthood: Tactile stimulation, nest odor, and social rearing prevent these effects. Dev. Psychobiol. 48:209-219.

Mendoza, A., D. Cavestany, G. Roig, J. Ariztia, C. Pereira, A. La Manna, D. A. Contreras, and C. S. Galina. 2010. Effect of restricted suckling on milk yield, composition and flow, udder health, and postpartum anoestrus in grazing Holstein cows. Livest. Sci 127:60-66. 
Metz, J. 1987. Productivity aspects of keeping dairy cow and calf together in the post-partum period. Livest. Prod. Sci. 16:385-394.

Miller, L. J. 2002. Postpartum depression. JAMA 287:762-765.

Moloney, R. D., O. F. O'Leary, D. Felice, B. Bettler, T. G. Dinan, and J. F. Cryan. 2012. Early-life stress induces visceral hypersensitivity in mice. Neurosci. Lett. 512:99-102.

Msanga, Y. N., and M. J. Bryant. 2003. Effect of restricted suckling of calves on the productivity of crossbred dairy cattle. Trop. Anim. Health Prod. 35:69-78.

Mukasa-Mugerwa, E., A. Tegegne, and R. Franceschini. 1991. Influence of suckling and continuous cow-calf association on the resumption of post-partum ovarian function in Bos indicus cows monitored by plasma progesterone profiles. Reprod. Nutr. Dev. 31:241-247.

Murgatroyd, C. A., and B. C. Nephew. 2013. Effects of early life social stress on maternal behavior and neuroendocrinology. Psychoneuroendocrinology 38:219-228.

Musselman, D. L., D. L. Evans, and C. B. Nemeroff. 1998. The relationship of depression to cardiovascular disease-Epidemiology, biology, and treatment. Arch. Gen. Psychiatry 55:580-592.

Negrão, J. A., and P. Marnet. 2002. Effect of calf suckling on oxytocin, prolactin, growth hormone and milk yield in crossbred Gir $\times$ Holstein cows during milking. Reprod. Nutr. Dev. 42:373-380.

Newberry, R. C., and J. C. Swanson. 2008. Implications of breaking mother-young social bonds. Appl. Anim. Behav. Sci. 110:3-23.

Nishi, M., N. Horii-Hayashi, and T. Sasagawa. 2014. Effects of early life adverse experiences on the brain: Implications from maternal separation models in rodents. Front. Neurosci. 8:166.

Oltenacu, P. A., and D. M. Broom. 2010. The impact of genetic selection for increased milk yield on the welfare of dairy cows. Anim. Welf. 19:39-49.

Orihuela, A., and C. Hernández. 2007. Cortisol response of restricted suckling or artificially milk-feeding to a short-term emotional stressor in dairy calves and their dams. Anim. Welf. 16:49-52.

Pérez-Torres, L., A. Orihuela, M. Corro, I. Rubio, M. A. Alonso, and C. S. Galin. 2016. Effects of separation time on behavioral and physiological characteristics of Brahman cows and their calves. Appl. Anim. Behav. Sci. 179:17-22.

Provenza, F. D., and D. F. Balph. 1987. Diet learning by domestic ruminants-Theory, evidence and practical implications. Appl. Anim. Behav. Sci. 18:211-232.

Punzo, F., and L. Ludwig. 2002. Contact with maternal parent and siblings affects hunting behavior, learning, and central nervous system development in spiderlings of Hogna carolinensis (Araeneae: Lycosidae). Anim. Cogn. 5:63-70.

Rørvang, M. V., B. L. Nielsen, M. S. Herskin, and M. B. Jensen. 2018 Prepartum maternal behavior of domesticated cattle: A comparison with managed, feral, and wild ungulates. Front. Vet. Sci. 5:45.

Roth, B. A., K. Barth, L. Gygax, and E. Hillmann. 2009. Influence of artificial vs. mother-bonded rearing on sucking behaviour, health and weight gain in calves. Appl. Anim. Behav. Sci. 119:143-150.

Sachser, N., M. B. Hennessy, and S. Kaiser. 2011. Adaptive modulation of behavioural profiles by social stress during early phases of life and adolescence. Neurosci. Biobehav. Rev. 35:1518-1533.

Sandem, A., and B. O. Braastad. 2005. Effects of cow-calf separation on visible eye white and behaviour in dairy cows - A brief report. Appl. Anim. Behav. Sci. 95:233-239.

Sanh, M. V., T. R. Preston, and P. Fajersson. 1995. Effects of restricted suckling versus artificial rearing on performance and fertility of Bos taurus and Bos indicus cows and calves in Tanzania. Livest. Res. Rural Dev. 6:29.

Sanh, M. V., T. R. Preston, and L. V. Ly. 1997. Effects of restricted suckling versus artificial rearing on performance and fertility of crossbreed F1 (Holstein Friesian $\times$ local) cows and calves in Vietnam. Livest. Res. Rural Dev. 9:31.
Stěhulová, I., L. Lidfors, and M. Špinka. 2008. Response of dairy cows and calves to early separation: Effect of calf age and visual and auditory contact after separation. Appl. Anim. Behav. Sci. 110:144-165.

Stěhulová, I., B. Valnickova, R. Sarova, and M. Spinka. 2017. Weaning reactions in beef cattle are adaptively adjusted to the state of the cow and the calf. J. Anim. Sci. 95:1023-1029.

Stein, M., A. H. Miller, and R. L. Trestman. 1991. Depression, the immune-system, and health and illness-Findings in search of meaning. Arch. Gen. Psychiatry 48:171-177.

Sumner, C. L., and M. A. G. von Keyserlingk. 2018. Canadian dairy cattle veterinarian perspectives on calf welfare. J. Dairy Sci. 101:10303-10316.

Teeluck, J. P., B. Hulman, and T. R. Preston. 1981. Effect of milking frequency in combination with restricted suckling on milk yield and calf performance. Trop. Anim. Prod. 6:138-145.

Thomas, G. W., S. A. Spiker, and F. Mickan. 1981. Influence of suckling by Friesian cows on milk production and anoestrus. Aust. J. Exp. Agric. 21:5-11.

Vaarst, M., M. B. Jensen, and A. Sandager. 2001. Behaviour of calves at introduction to nurse cows after the colostrum period. Appl. Anim. Behav. Sci. 73:27-33.

Veissier, I., S. Care, and D. Pomies. 2013. Suckling, weaning, and the development of oral behaviours in dairy calves. Appl. Anim. Behav. Sci. 147:11-18.

Ventura, B. A., M. A. von Keyserlingk, C. A. Schuppli, and D. M. Weary. 2013. Views on contentious practices in dairy farming: The case of early cow-calf separation. J. Dairy Sci. 96:6105-6116.

Ventura, B. A., M. A. von Keyserlingk, H. Wittman, and D. M. Weary. 2016. What difference does a visit make? Changes in animal welfare perceptions after interested citizens tour a dairy farm. PLoS One 11:e0154733.

Vitale, A. F., M. Tenucci, M. Papini, and S. Lovari. 1986. Social behaviour of the calves of semi-wild Maremma cattle, Bos primigenius taurus. Appl. Anim. Behav. Sci. 16:217-231.

von Keyserlingk, M. A. G., and D. M. Weary. 2007. Maternal behavior in cattle. Horm. Behav. 52:106-113.

Wagenaar, J., and J. Langhout. 2007. Practical implications of increasing 'natural living' through suckling systems in organic dairy calf rearing. NJAS Wagening. J. Life Sci. 54:375-386.

Wagner, K., K. Barth, E. Hillmann, R. Palme, A. Futschik, and S. Waiblinger. 2013. Mother rearing of dairy calves: Reactions to isolation and to confrontation with an unfamiliar conspecific in a new environment. Appl. Anim. Behav. Sci. 147:43-54.

Wagner, K., K. Barth, R. Palme, A. Futschik, and S. Waiblinger. 2012. Integration into the dairy cow herd: Long-term effects of mother contact during the first twelve weeks of life. Appl. Anim. Behav. Sci. 141:117-129.

Wagner, K., D. Seitner, K. Barth, R. Palme, A. Futschik, and S. Waiblinger. 2015. Effects of mother versus artificial rearing during the first 12 weeks of life on challenge responses of dairy cows. Appl. Anim. Behav. Sci. 164:1-11.

Walsh, J. P. 1974. Milk secretion in machine-milked and suckled cows. Isr. J. Agric. Res. 13:77-89.

Weary, D. M., and B. Chua. 2000. Effects of early separation on the dairy cow and calf: 1 . Separation at $6 \mathrm{~h}, 1$ day and 4 days after birth. Appl. Anim. Behav. Sci. 69:177-188.

Windle, R. J., S. Wood, N. Shanks, P. Perks, G. L. Conde, A. daCosta, C. D. Ingram, and S. L. Lightman. 1997. Endocrine and behavioural responses to noise stress: Comparison of virgin and lactating female rats during non-disrupted maternal activity. J. Neuroendocrinol. 9:407-414. 


\section{APPENDIX}

\section{Quality of Evidence}

All studies that met our inclusion criteria are reported; however, reasons for caution exist in drawing conclusions in some cases. Given the age of some studies included and the practical difficulties of conducting such work, sample sizes were often low. Of the 24 studies reporting behavioral measures, none reported interobserver reliability, although 2 reported pretraining to ensure consistency and 2 mentioned using a single consistent observer. Only 1 study used blind observers for behavioral data (Windle et al., 1997), and an additional study used blinding in coding heart rate data (Wagner et al., 2012). The limited use of blinding is not surprising given that blinding observers to treatment is not possible if cows are with the calves during observation.

Several papers were also missing relevant information, making interpretation challenging (e.g., one failed to report actual sample size: Wagenaar and Langhout, 2007). Of the studies examined for calf growth, 7 of the 21 studies failed to describe the amount of contact in the control group, and 3 were missing relevant details about feeding. One of the milk yield papers was missing details about the type of suckling system used. One paper on the behavioral effects (Wagner et al., 2013) also had missing data in the analyses; the omission was not explained, increasing the risk of bias in the reported results. In Buchli et al. (2017), which compared behavioral and cortisol responses to novelty and social companions across farms, it is unclear whether tests were conducted before or after removal from the dam.

\section{Risk of Bias Across Studies}

We used a single search engine, which may have caused us to miss some relevant papers. Web of Science is comprehensive, and the use of the reference lists as an additional source should have minimized the number of papers missed, especially those in which the keywords did not appear in the abstract or title and thus would not have been identified by Web of Science. This point is particularly important because nonsignificant results might be less likely to appear in these parts of the paper. Full texts were available for all relevant papers found in the initial Web of Science search, and just 3 papers from the reference lists could not be accessed to check for relevance; therefore, a major bias introduced through limited access was unlikely. Limiting the search to English papers did result in the exclusion of several studies before screening for relevance, but the majority of these were limited to 1 or 2 research groups located in Europe. No systematic difference is expected between these papers and those included in this review.

The research included in this review is predominantly from North America and northern and western Europe, with a few studies from tropical countries. Thus, the reviewed studies may not be representative of practices in other areas of the world, including grazing-based systems common in parts of South America and Oceania.

Publication bias due to influence from funding sources seems unlikely. While some studies declared funding from industry and a few declared funding from animal welfare organizations, the majority of declared funding was from national research councils and universities.

\section{Inconsistencies in Methods, Possible Confounding Factors, and Common Problems}

As discussed above, both the treatments and the methods of assessment varied across studies in ways that could affect the conclusions. This lack of consistency and the limited number of studies per outcome variable made meta-analysis infeasible. The feeding and housing of calves after separation also varied; many studies used individual housing for the artificially reared calves, a factor known to affect behavioral outcomes (e.g., see Duve et al., 2012; Meagher et al., 2015). Artificially reared calves in the older studies were also often provided restricted amounts of milk, likely influencing growth and abnormal behavior, which could have led to ceiling effects.

Although most papers did not have very small sample sizes, some may not have been sufficient for detecting differences in what are likely to be noisy data. This includes studies on yield (e.g., $\mathrm{n}=12$ : Negrão and Marnet 2002, who reported no effect) and behavioral outcomes measured long after the period of contact. 